\title{
Prevalence, Knowledge and Treatment of Systemic Arterial Hypertension in A Campaign Day
}

\author{
Elizabeth Do Espirito Santo Cestário, Anderson Aparecido Santim, Beatriz Beretta Alves, Beatriz \\ Pereira Alcarde, Beatriz Sanches Rodrigues, Catarina de Souza Nascimento, Fernanda de Almeida \\ Spósito, Lauane Carolina Maciel Fernandes, Letícia Fernandes Garcia, Roberta Bonamim Fiorilli, \\ Vinícius Cardoso de Leão, Vinícius Cavallari
}

\section{ABSTRACT}

Hypertension affects 1.4 billion of the world population, being considered the main cause of cardiovascular diseases and, therefore, an important cause of premature and preventable mortality worldwide. It is associated with complications such as atherosclerotic coronary artery disease, congestive heart failure, stroke, intracerebral hemorrhage, and chronic kidney disease. Given this prevalence and risk, strategies were created to control the disease, such as changes in lifestyle and use of medications. However, non-adherence to treatment is a frequent concern and it is associated with adverse results and an increased number of complications. Therefore, the present study aims to present the incidence of arterial hypertension in the population of a city in the inland part of São Paulo, relating it to its risk factors, adherence to treatment and disease control. The objective is evaluating the incidence and rate of uncontrolled systemic arterial hypertension on a campaign day in a city in the inland part of São Paulo. The method is observational, cross-sectional, descriptive, populationbased study, random sample of 545 individuals, 231 women and 314 men, collected in a city in the northwest of São Paulo on a campaign day. The study showed a prevalence of $46.24 \%$ for hypertensive patients, with $88.9 \%$ adherence to treatment and pressure loss of $34.23 \%$. Among the analyzed hypertensive patients, there was a higher incidence among the elderly, obese, and people with diabetes mellitus. Regarding adherence and disease control, better results were noted among patients with complications such as $\mathrm{AMI}$ and thrombotic events, and less adherence among obese, alcoholics and smokers. The results of the present study are consistent with literature data, showing that even with knowledge of the disease, part of the population does not have adequate treatment, showing the need for integrated health policies for early diagnosis, distribution and treatment regulation, and actions to improve lifestyle.

Keywords: Cardiovascular disease, hypertension, uncontrolled hypertension.

Submitted : November 1, 2021

Published : January 13, 2022

ISSN: 2593-8339

DOI: $10.24018 /$ ejmed.2022.4.1.1126

\section{E. E. S. Cestario}

University Center of Votuporanga, São Paulo, Brazil.

(e-mail: cestario@cardiol.br)

A. A. Santim

University Center of Votuporanga, São Paulo, Brazil.

B. B. Alves

University Center of Votuporanga, São Paulo, Brazil.

B. P. Alcarde

University Center of Votuporanga, São Paulo, Brazil.

B. S. Rodrigues

University Center of Votuporanga, São Paulo, Brazil.

C. S. Nascimento

University Center of Votuporanga, São

Paulo, Brazil.

F. A. Sposito

University Center of Votuporanga, São Paulo, Brazil.

L. C. M. Fernandes

University Center of Votuporanga, São Paulo, Brazil.

L. F. Garcia

University Center of Votuporanga, São Paulo, Brazil.

R. B. Fiorilli

University Center of Votuporanga, São Paulo, Brazil.

V. C. Leão

University Center of Votuporanga, São

Paulo, Brazil.

V. Cavallari

University Center of Votuporanga, São Paulo, Brazil.

*Corresponding Author

\section{INTRODUCTION}

The increase in blood pressure is defined, according to the American College of Cardiology (ACC) and the American Heart Association (AHA), as Blood Pressure (BP) $\geq 130 / 80$ $\mathrm{mm} \mathrm{Hg}$. Currently, it affects 1.4 billion people of the world population, being considered the main cause of cardiovascular diseases and, therefore, an important cause of premature and preventable mortality worldwide. Among its risk factors are genetic and behavioral factors, such as age, race, family history, obesity, diet, physical inactivity and consumption of tobacco and alcohol [1]-[3]. In relation to complications, the increase in blood pressure can lead to atherosclerotic coronary artery disease, heart failure (HF), 
stroke, intracerebral hemorrhage and chronic kidney disease (CKD). It represents an association with $47 \%$ of all ischemic heart disease events and $54 \%$ of all strokes in the world [1].

Given this prevalence and risk, strategies were created to control the disease, such as changes in lifestyle and use of medications. However, non-adherence to treatment is a frequent concern and it is associated with adverse results and an increased number of complications. To date, there has been no systemic review or meta-analysis carried out to quantify and justify non-adherence, which hampers interventions and strategies to improve this reality [4]-[6].

Among the forms of control, several studies have demonstrated lifestyle modification approaches to reduce or prevent hypertension. Reducing body weight, performing regular physical activities, reducing salt or sodium intake, increasing potassium supplementation and avoiding harmful alcohol use are recommended. Regarding healthy eating, the Dietary Approaches to Stop Hypertension (DASH) argues that it can result in increased intake of potassium, magnesium, calcium and fibers, and research shows that it can reduce blood pressure, improve the lipid profile, contribute to glycemic control and reduce cardiovascular risk [7], [8].

As for the change in lifestyle, governments were encouraged to invest in population strategies and promote their individual management. In this context, current guidelines recommend physical activity and regular exercise as part of first-line therapy in primary and secondary prevention of hypertension [9].

Among antihypertensive agents, it has been observed that initial low-dose treatment with two or three antihypertensive agents is more effective than the standard dose of monotherapy. However, the number of pills can have an influence on medical adherence. Recent data indicate that an increase in the number of antihypertensive drugs would lead to loss of clinical adherence by up to $80 \%$, increasing the risk of complications [10].

As chronic diseases are responsible for a large number of hospitalizations and mortality, their prevention is the best way to improve the population's quality of life and public spending, after all, more than 1 billion adults lived with hypertension in 2015, and the majority in low- and middleincome countries [11].

\section{OBJECTIVES}

To evaluate the lack of control of Systemic Arterial Hypertension during a campaign day in a city in the inland part of São Paulo. For this, the prevalence of hypertensive patients was evaluated, as well as the presence of risk factors and associated complications. In addition, the adherence to drug treatment in hypertensive patients who participated on the day of the campaign and the lack of knowledge about the diagnosis of SAH on the day of the campaign.

\section{CASUISTIC AND Methods}

Observational, cross-sectional, descriptive, populationbased study, random sample collected in a city in the northwest of São Paulo on a campaign day.

The sample comprised 545 individuals, 231 women and
314 men randomly selected from individuals who passed downtown and who agreed to participate in the project. After clarifying that the data collected would be anonymous, they authorized their data to be later used for academic purposes

The instrument used was a data collection form sent by the International Hypertension Society, which contained the variables: sex, age, height, weight, ethnicity, BP measurement in the last 12 months, previous diagnosis of $\mathrm{SAH}$ and diabetes mellitus, continuous use of antihypertensive medications, smoking, alcohol consumption, history of acute myocardial infarction (AMI) or previous thrombosis. Regarding the measurements, weight and height were evaluated using a digital scale, BP measurement with a manual BIC sphygmomanometer on the left arm with three BP measurements and counting of three heart rates, both at 1-minute intervals each.

$\mathrm{SAH}$ was considered as systolic $\mathrm{BP} \geq 140 \mathrm{~mm} \mathrm{Hg}$ and/or diastolic $\mathrm{BP} \geq 90 \mathrm{~mm} \mathrm{Hg}$ (considering the average of 3 measurements, with an interval of 1 minute each) and/or positive answer to the question "Are you currently taking medication to decrease your BP?". Hypertension awareness was determined by hypertensive patients who answered affirmatively to the question: "Have you ever been told by a doctor or other health professional that you had hypertension, also called high blood pressure?". The treatment of hypertension was established by the participants who answered "yes" to the question: "Due to your hypertension/high blood pressure, are you taking prescription drugs?".

The event was organized by the Academic League of Cardiology of Medicine of Votuporanga. Data collection was performed by students from different courses in the health field, such as medicine, biomedicine, nursing, and nutrition, who had knowledge about BP measurement.

\section{RESULTS}

The mean values of systolic blood pressure (SBP) and diastolic pressure (DBP) were 124.96 and $79.85 \mathrm{mmHg}$, respectively.

Considering only the 252 participants diagnosed with Systemic Arterial Hypertension (SAH), 109 (43.25\%) were women and $143(56.75 \%)$ men. SBP and DBP, respectively, were $125.92 \times 80.53 \mathrm{mmHg}$ in males and $123.69 \times 79.07$ $\mathrm{mmHg}$ in females. The prevalence of $\mathrm{SAH}$ in women was higher than in men ( $47.19 \%$ and $45.54 \%$, respectively). It is noted that men have slightly better adherence to treatment $(88.11 \% \times 88.07 \%)$ and a lower proportion of individuals with uncontrolled pressure $(31.75 \%$ x $34.37 \%)$, but greater ignorance about being carriers of disease (47.87\% x 36.06\%).

The average age of the participants was 58.37 years. Hypertensive patients have a higher average age compared to those who do not have the disease $(60.98 \times 56.13$ years, respectively). The study included $49.72 \%$ of the elderly and $50.28 \%$ of individuals under 60 years of age. When performing a comparative analysis between the two groups, it is noted that in the elderly there is a higher prevalence of SAH $(52.04 \% \times 40.44 \%)$ and greater ignorance about being comorbid (44.00\% $\mathrm{x} 42.50 \%)$, however, they adhere better to the treatment $(95.71 \% \times 78.18 \%)$, and have a lower rate of uncontrolled pressure values (29.85\% x $38.37 \%)$. 
The study had 180 (33.03\%) self-declared drinkers, whose prevalence of hypertension was $45.55 \%$. When comparing them to non-drinkers, there is less adherence to the treatment of SAH ( $82.93 \%$ drinkers x $90.59 \%$ non-drinkers) and greater uncontrolled blood pressure levels $(33.82 \%$ drinkers $\mathrm{x}$ $32.47 \%$ non-drinkers). However, the group of non-alcoholics has a higher proportion of individuals without a diagnosis of SAH and with high blood pressure on the day of the event $(47.54 \% \times 71.27 \%)$, indicating greater ignorance about the pathology.

Among the 545 participants, 69 (12.66\%) claimed to be smokers. The rate of hypertensive patients in this group corresponded to $31.88 \%$. When analyzing the group of smokers and non-smokers and comparing them, respectively, it was concluded that smokers have less adherence to the use of antihypertensive drugs $(68.18 \% \times 90.00 \%)$, greater uncontrolled blood pressure $(40,00 \% \times 32.37 \%)$ and greater ignorance about having SAH (67.85\% x 37.79\%).

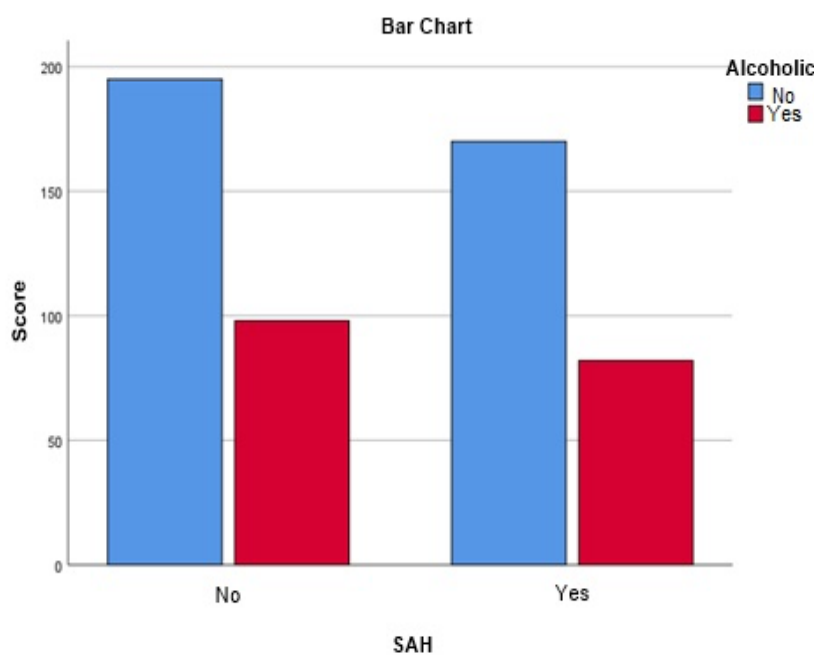

Fig. 1. Alcoholic xSAH.

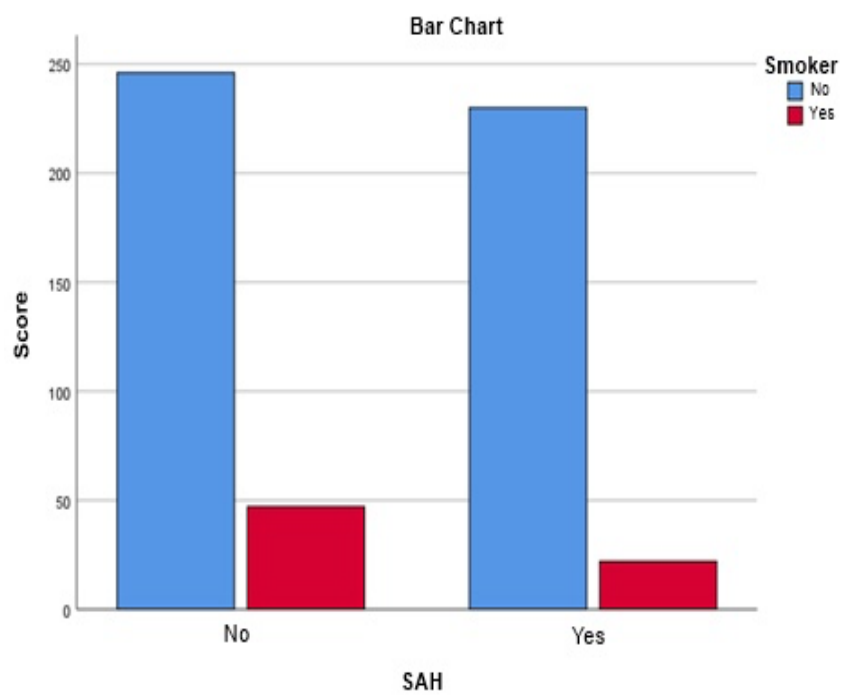

Fig. 2. Smokers.

From all the individuals, 79 (14.49\%) were diabetic. The prevalence of SAH in this group was $69.62 \%$. Performing a comparative analysis between diabetics and non-diabetics, respectively, it is observed that diabetics have better adherence to treatment $(94.54 \%$ x $86.29 \%)$, less uncontrolled pressure values $(26.92 \%$ x $34.71 \%)$ and lower proportion of individuals without previous diagnosis of SAH with high blood pressure values on the day of the event $(33.33 \% \mathrm{x}$ $45.04 \%)$.

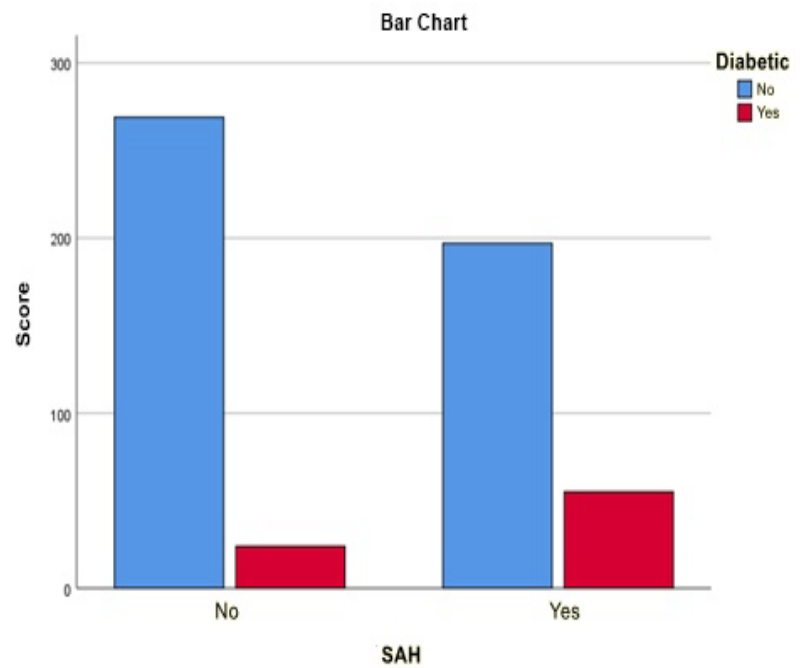

Fig. 3. Diabetic x SAH.

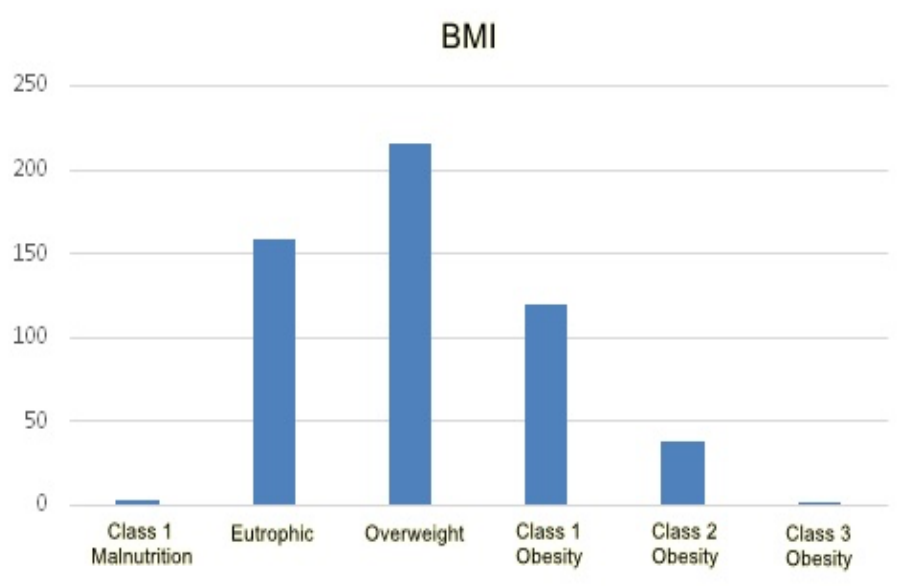

Fig. 4. Body Mass Index x Obesitty.

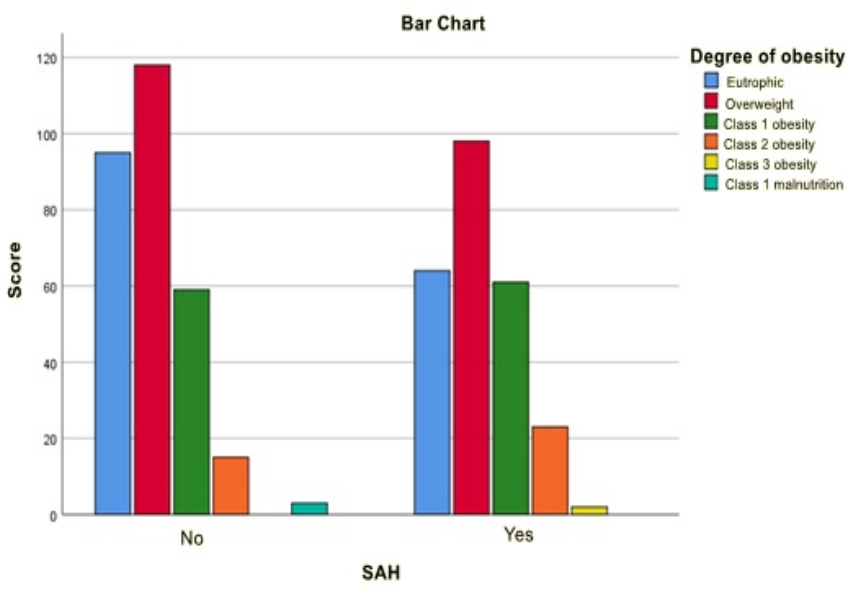

Fig 5. Obesity x SAH.

In total, 160 (29.68\%) participants were obese. Of these, $53.75 \%$ were hypertensive. It is noted that the prevalence of SAH increases as the BMI increases, as well $(40.25 \%$ in healthy individuals; $45.37 \%$ in overweight; $50.83 \%$ in class 1 
obesity; $60.53 \%$ in class 2 obesity and $100 \%$ in class 3 obesity). When correlating them with the non-obese, it is observed that the obese adhere less to the treatment $(84.88 \%$ x $89.44 \%$ ), have greater pressure loss $(35.62 \%$ x $31.94 \%)$, however they have less proportion of individuals with high blood pressure levels without previous diagnosis of SAH (41.67\% x 44.68\%).

One of the possible complications for patients with SAH is Acute Myocardial Infarction (AMI). Of the 545 people, 31 $(5.69 \%)$ had a history of AMI. The prevalence of SAH in these individuals was $67.74 \%$. When comparing the participants with and without previous ischemic cardiac events, respectively, it is noted that those who already had a heart attack have greater adherence to the treatment of SAH $(95.24 \%$ x $87.45 \%)$, less uncontrolled pressure values $(25.00$ $\% \times 33.66 \%$ ) and a smaller proportion of people who were not diagnosed with SAH but had high BP on the day of the event $(33.33 \%$ x $44.44 \%)$.

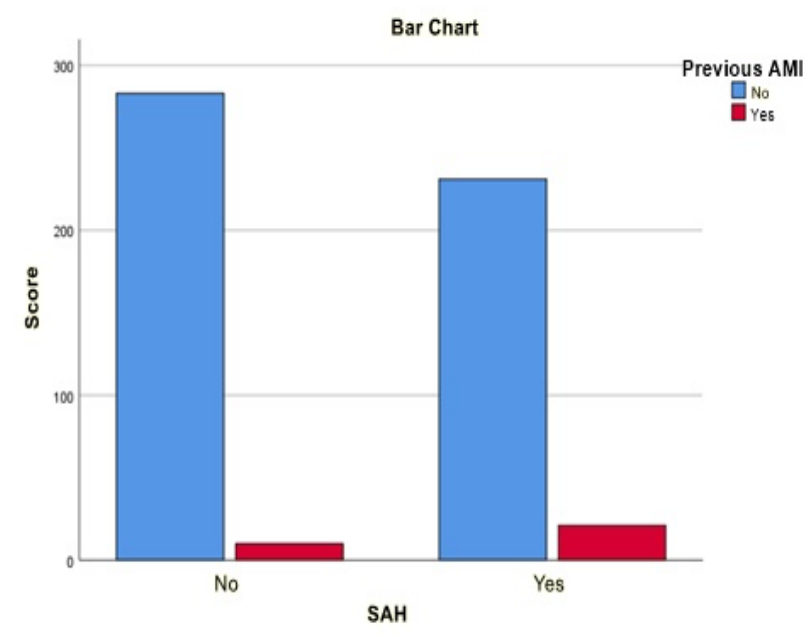

Fig. 6. Previous AMI x SAH.

Another common complication in hypertensive patients is thrombotic events. The study obtained $8(1.47 \%)$ people with a previous history of thrombosis. The prevalence of hypertension in this group was $62.50 \%$. When analyzing individuals with and without a thrombotic history and comparing them, respectively, it was concluded that those who had a previous thrombosis episode adhere better to the treatment (100.00\% x 87.85\%), have less uncontrolled blood pressure values $(20.00 \% \times 33.18 \%)$ and better knowledge about having $\mathrm{SAH}$, since all members of this group with high blood pressure had a previous diagnosis, while $43.51 \%$ of the group without a history of thrombosis had high BP without being previously diagnosed as hypertensive.

The overall prevalence of hypertension in the study was $46.24 \%$, with a rate of adherence to treatment of $88.09 \%$ and uncontrolled pressure levels in $34.23 \%$ of hypertensive patients. In addition, $43.23 \%$ of individuals with high BP at the event were not diagnosed with $\mathrm{SAH}$ and $7.74 \%$ were diagnosed, but they were not using antihypertensive medications.

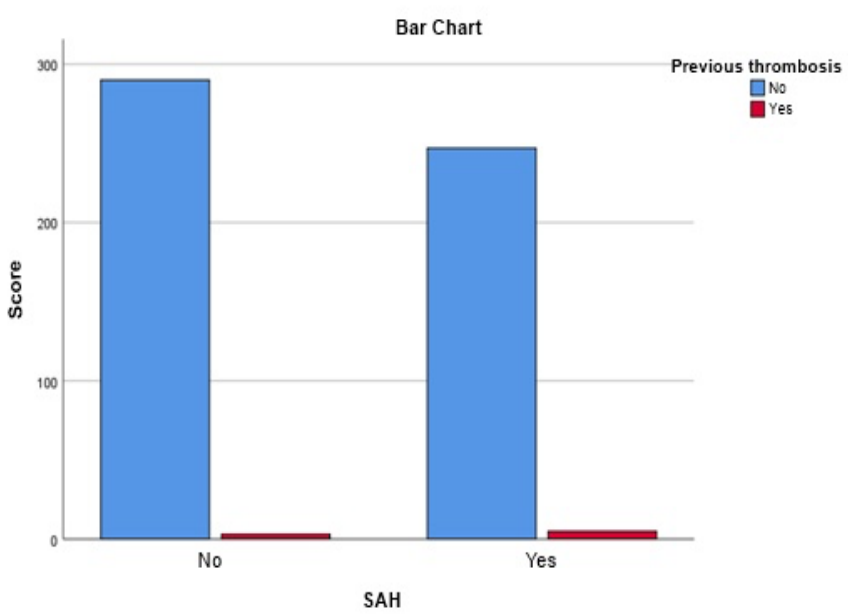

Fig. 7. Trombosis $\mathrm{x}$ SAH.

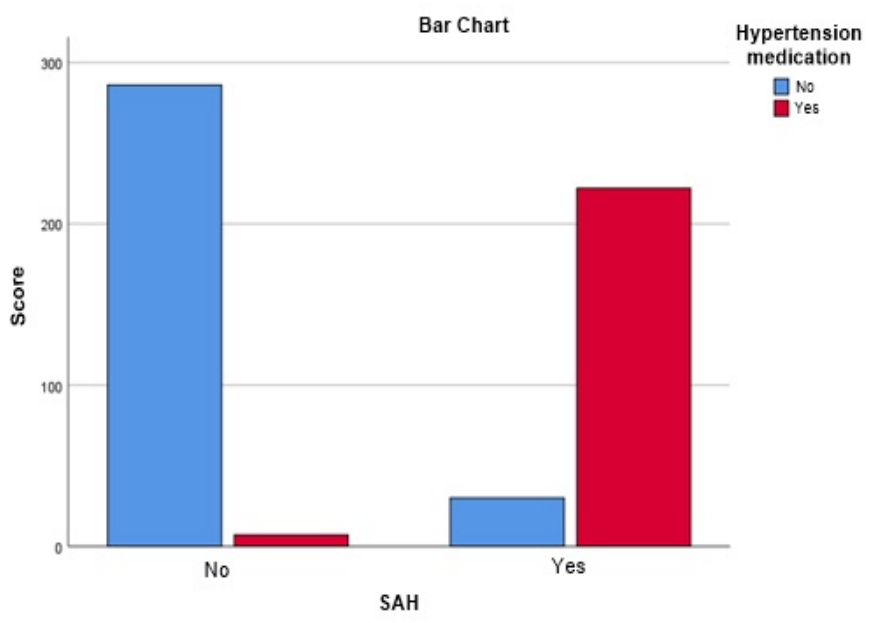

Fig. 8. Anhypertesives drugs x SAH.

In comparisons between hypertensive and nonhypertensive individuals, respectively, with the variables present in the study, it is noted that hypertensive individuals are older (60.98 years x 56.13 years), have greater weight $(77.77 \mathrm{~kg} \times 74.90 \mathrm{~kg})$, shorter height $(148.85 \mathrm{~cm} \times 152.09$ $\mathrm{cm}$ ), higher SBP and DBP (127.70 and $81.50 \mathrm{mmHg} \times 122.61$ and $78.43 \mathrm{mmHg}$ ), greater relationship with obesity $(34.68 \%$ x $25.52 \%)$ and diabetes Melitus $(21.83 \%$ x $8.19 \%)$, lower prevalence of alcoholism (32.41\% x 33.45\%) and smoking $(8.73 \% \times 16.04 \%)$, and a higher occurrence of complications such as AMI $(8.33 \%$ x $3.41 \%)$ and thrombotic events $(1.98 \%$ x $1.02 \%)$.

TABLE I: BLOOD PRESSURE GENERAL MEAN

\begin{tabular}{cccc}
\hline \hline & \multicolumn{3}{c}{ General } \\
\hline \hline Age & 58,370 & Standard Deviation & $\begin{array}{c}\text { Confidence Interval } \\
(95 \%)\end{array}$ \\
HR & 72,630 & 13,695 & $(57,216-59,524)$ \\
SBP & 124,964 & 11,149 & $(71,694-73,566)$ \\
DBP & 79,857 & 15,422 & $(123,669-126,259)$ \\
MBP & 94,893 & 11,051 & $(78,929-80,785)$ \\
PP & 45,107 & 11,500 & $(93,928-95,858)$ \\
BMI & 27,653 & 11,313 & $(44,157-46,057)$ \\
\hline \hline
\end{tabular}


TABLE II: BLOOD PRESSURE X GENDER

\begin{tabular}{ccccccc}
\hline \hline & \multicolumn{2}{c}{ Male } & & \multicolumn{2}{c}{ Female } \\
\hline \hline & Mean & Standard Deviation & Confidence Interval (95\%) & Mean & Standard Deviation & Confidence Interval (95\%) \\
\hline \hline Age & 59,680 & 13,122 & $(58,210-61,140)$ & 56,470 & 14,295 & $(54,600-58,340)$ \\
HR & 71,960 & 11,589 & $(70,670-73,260)$ & 73,640 & 10,665 & $(72,250-75,040)$ \\
SBP & 125,924 & 15,690 & $(124,171-127,678)$ & 123,695 & 15,080 & $(121,718-125,671)$ \\
DBP & 80,536 & 11,359 & $(79,266-81,805)$ & 79,075 & 10,753 & $(77,666-80,485)$ \\
MBP & 95,665 & 11,703 & $(94,357-96,973)$ & 93,948 & 11,317 & $(92,465-95,432)$ \\
PP & 45,390 & 11,832 & $(44,070-46,710)$ & 44,620 & 10,567 & $(43,230-46,000)$ \\
BMI & 27,826 & 4,378 & $(27,340-28,312)$ & 27,416 & 4,637 & $(26,813-29,019)$ \\
\hline \hline
\end{tabular}

TABLE III: BLOOD PRESSURE MEAN

\begin{tabular}{ccccccc}
\hline \hline & Hypertensive & & \multicolumn{2}{c}{ Non-hypertensive } \\
\hline \hline & Mean & Standard Deviation & Confidence Interval (95\%) & Mean & Standard Deviation & Confidence Interval (95\%) \\
Age & 60,980 & 13,112 & $(59,361-62,599)$ & 56,130 & 13,810 & $(54,549-57,711)$ \\
HR & 72,144 & 11,735 & $(70,695-73,593)$ & 73,048 & 10,622 & $(71,832-74,264)$ \\
SBP & 127,706 & 15,387 & $125,806-129,606)$ & 122,606 & 15,084 & $(120,879-124,333)$ \\
DBP & 81,516 & 11,476 & $(80,099-82,933)$ & 78,430 & 10,482 & $(77,230-79,630)$ \\
MBP & 96,913 & 11,551 & $(95,487-98,339)$ & 93,155 & 11,187 & $(91,874-94,436)$ \\
PP & 46,190 & 12,240 & $(44,679-47,701)$ & 44,176 & 10,381 & $(42,987-45,365)$ \\
BMI & 27,716 & 4,392 & $(27,168-28,264)$ & 27,600 & 4,577 & $(27,075-28,125)$ \\
\hline \hline
\end{tabular}

\section{DISCUSSION}

According to the World Health Organization (WHO), the number of individuals with SAH has increased significantly in the last 40 years, with an estimated 1.5 billion hypertensive individuals for the year 2025. Globally, Africa is the country with the highest index of SAH, with $27 \%$ of the hypertensive population, followed by the regions of the Eastern Mediterranean, Southeast Asia (25\%) and Europe (23\%). The lowest incidences were found in the Americas (18\%) and the Western Pacific region (19\%) [12], [13].

In Brazil, the disease is estimated at 36 million adult individuals, contributing directly or indirectly to $50 \%$ of deaths from cardiovascular disease. Associated with diabetes mellitus (DM) and its cardiac, renal and vascular complications, it has a high impact on the loss of work productivity and family income, estimated at US \$4.18 billion between 2006 and 2015. However, it is important to note that, in Brazil, the prevalence of arterial hypertension varies according to the population studied and the evaluation method [14], [15].

AHA updates in 2019 point to an estimated 116.4 million (46\%) adults in the U.S. with hypertension [16]. The overall prevalence of hypertension in the study was $46.24 \%$, similar to the result corroborated above, with a rate of adherence to treatment of $88.09 \%$ and uncontrolled pressure levels in $34.23 \%$ of hypertensive patients. In addition, $43.23 \%$ of individuals with high BP at the event were not diagnosed with SAH.

The control of blood pressure within the target plays a critical role in reducing associated CVD; however, in analysis, the rate of uncontrolled blood pressure levels in this study was $34.23 \%$ for hypertensive patients.

Diverging from the results obtained, the metanalysis of Amare et al. in Ethiopia found a prevalence of uncontrolled hypertension among hypertensive patients undergoing treatment of $48 \%$ [2].

Similar values related to the lack of control of SAH have been found in several populations. Populations from 90 countries worldwide showed a rate of $62.9 \%$, low- and middle-income countries showed a lack of control of $73.7 \%$ : with emphasis on rural India (89.7\%), urban India (79.8\%) and China (91.9\%). In another meta-analysis in Brazil, there was a lack of control of $68.2 \%$ in men and $43.1 \%$ in women, all highly above the current study [2].

However, inferior results of uncontrolled hypertension were found in Dutch (30\%), English (23.9\%), Canadian (14\%) and American (21.2\%) studies [2]. Thus, the high prevalence of uncontrolled hypertension observed in this study may be associated with socioeconomic factors, low educational level and poverty.

A 2017 study from Spain showed that one in three adults is hypertensive, with only half of those undergoing treatment adequately controlling the disease, resulting in 40,000 cardiovascular deaths annually attributable to the disease. 17

In an American study, the prevalence of hypertension according to National Health and Nutrition Surveys (NHANES) of the US population aged $\geq 18$ years in 2008 , there are approximately 67.5 million hypertensive adults in the United States, with more than 33 million people with uncontrolled SAH. However, the proportion of hypertensive patients with uncontrolled blood pressure decreased from $73.2 \%$ in 1988 to 1994 to $52.5 \%$ in 2005 to 2008 [18].

In reference to a Russian study among hypertensive patients, regardless of treatment, blood pressure control was achieved in $22 \%$ of men while in women it was $33 \%$ [19].

Individuals in Russia were more likely to lose control of hypertension, with $55.7 \%$ in men and $42.7 \%$ in women compared to Norway, where the corresponding percentages were $43.6 \%$ and $33.0 \%$. 36 In the present study, the rates of uncontrolled hypertension in women and men were $34.37 \%$ and $31.75 \%$, respectively, with differences in relation to uncontrolled and sex rates [19].

Ultimately, this study showed a SAH control rate of approximately $70 \%$ in the elderly population. Another Brazilian study showed results that differed from this one, in which only half $(50.7 \%)$ of the elderly Brazilian hypertensive population undergoing drug treatment had controlled blood pressure levels. Comparatively, the prevalence of controlled 
blood pressure levels among elderly hypertensive patients, who used medication, was higher than that observed in Canada (66\%), the United States (48\%) and in populations in developing countries (between 20 and 36\%) [20].

On average, the controlled percentage of SAH in the Arab countries is comparable to the $8 \%$ and $23 \%$ reported for the USA and European countries, respectively [21].

According to the National Health and Nutrition Surveys (NHANES) of the US population aged $\geq 18$ years in 2008 of the 33 million people with uncontrolled SAH, approximately 13 million of the uncontrolled hypertensive patients were unaware of the disease and only 20 million are aware of their hypertension [18].

With regard to awareness of hypertension, our findings of $43.23 \%$ of individuals with high BP at the event did not have the diagnosis of SAH corroborate those of economically developed countries, in which approximately half to two thirds of hypertensive patients were aware of their diagnosis. Limited access to health services, especially in rural areas, and the lack of preventive care coupled with the silent symptoms of SAH, may contribute to the lack of knowledge and the inadequate rate of control in the Arab population [21].

A study in an urban Indian population over 25 years old estimated rates of awareness, treatment and control of SAH of $42.0 \%, 37.6 \%$ and $20.2 \%$ for urban India and $25.3 \%$, $25.1 \%$ and $10.7 \%$ for rural India. Similar urban-rural differences have been reported in other low-income countries [22].

The prevalence of hypertension is lowest in Canada (19.5\%) and highest in the USA (29\%) and England (30\%). Awareness of hypertension is close to $80 \%$ in the USA (81\%), Canada (83\%) and lower in England (65\%). England also has lower levels of treatment for hypertension (England 51\%; USA 74\%; Canada 80\%) and control (England 27\%; USA $53 \%$; Canada 66\%). Among individuals treated for hypertension, the controlled proportion is lower in England (53\%), compared to $71 \%$ in the USA and $82 \%$ in Canada. 23

According to Van Rossum et al., several studies have shown that a considerable proportion of hypertensive patients are not aware of having a diagnosis of SAH and that, among those who are aware, a considerable proportion is not treated. However, awareness frequencies appear to vary substantially from $23 \%$ in China to $97 \%$ in women in the United States.

\section{CONCLUSION}

The results are consistent with literature data showing that even though they are aware of the disease, some patients are not adequately treated, since the prevalence of uncontrolled hypertension in this study was high. This is alarming, due to the increased risk of cardiovascular complications. Reality that imposes additional burdens on the country's health system, highlighting the need for public health policies in order to implement strategic interventions focused on achieving an ideal blood pressure among treated hypertensive patients.

Given these data, the challenge continues: to develop, in practice, measures that can improve BP control, the adherence of patients with SAH to treatment, as well as reducing the factors that influence their adherence.

Determining the prevalence of uncontrolled SAH will help understand the magnitude of the problem and develop strategies to reduce the imposed burden of CVD.

To combat these potentially adverse trends and improve the overall control of hypertension, integrated health policies are needed, from actions that guarantee the improvement of lifestyle with healthy habits, early diagnosis to public policies to guarantee the purchase, distribution and regular use of effective antihypertensive drugs.

\section{ABBREVIATIONS}

Acute Myocardial Infarction (AMI), American College of Cardiology (ACC), American Heart Association (AHA), Blood Pressure (BP), Chronic Kidney Disease (CRF), Diabetes Mellitus (DM), Heart failure (HF), MMM18 (May Measurement Month), National Health Survey (PNS), Systemic Arterial Hypertension (SAH), Stroke (Stroke), World Health Organization (WHO).

\section{REFERENCES}

[1] Liu MY, Li N, Li WA, Khan H. Association between psychosocial stress and hypertension: a systematic review and meta-analysis. Neurol Res. 2017; 39(6): 573-80.

[2] Amare F, Hagos B, Sisay M, Molla B. Uncontrolled hypertension in Ethiopia: a systematic review and meta-analysis of institution-based observational studies. BMC Cardiovasc Disord. 2020; 20(1): 129.

[3] Brunström M, Carlberg B. Benefits and harms of lower blood pressure treatment targets: systematic review and meta-analysis of randomized placebo-controlled trials. BMJ Open. 2019; 9(9): e026686

[4] Saneei P, Salehi-Abargouei A, Esmaillzadeh A, Azadbakht L. Influence of Dietary Approaches to Stop Hypertension (DASH) diet on blood pressure: a systematic review and meta-analysis on randomized controlled trials. Nutr Metab Cardiovasc Dis. 2014; 24(12): 1253-61.

[5] Payne Riches S, Piernas C, Aveyard P, Sheppard JP, Rayner M, Jebb SA. The Salt Swap intervention to reduce salt intake in people with high blood pressure: protocol for a feasibility randomized controlled trial. Trials. 2019; 20(1): 584.

[6] Abegaz TM, Shehab A, Gebreyohannes EA, Bhagavathula AS, Elnour AA. Nonadherence to antihypertensive drugs: A systematic review and meta-analysis. Medicine (Baltimore). 2017; 96(4): e5641.

[7] Saif-Ur-Rahman KM, Shariful Islam S, Hasan M, Hossain S, Mamun $\mathrm{R}$, Shafique $\mathrm{S}$, et al. Nonpharmacological interventions for the prevention of hypertension in low- and middle-income countries: a systematic review and meta-analysis. J Hum Hypertens. 2019.

[8] Bricarello LP, de Moura Souza A, de Almeida Alves M, Retondario A, Fernandes R, Santos de Moraes Trindade EB, et al. Association between DASH diet (Dietary Approaches to Stop Hypertension) andhypertension in adolescents: A cross-sectionalschool-basedstudy. ClinNutr ESPEN. 2020; 36: 69-75.

[9] Bersaoui M, Baldew SM, Cornelis N, Toelsie J, Cornelissen VA. The effect of exercise training on blood pressure in African and Asian populations: A systematic review and meta-analysis of randomized controlled trials. Eur J Prev Cardiol. 2019: 2047487319871233.

[10] Weisser B, Predel HG, Gillessen A, Hacke C, EscheJvd, Rippin G, et al. Single pill regimen leads to better adherence and clinical outcome in daily practice in patients suffering from hypertension and/or dyslipidemia: results of a meta-analysis. High Blood Pressure \& Cardiovascular Prevention. 2020; 27(2): 157.

[11] Song P, Zhang Y, Yu J, Zha M, Zhu Y, Rahimi K, et al. Global Prevalence of Hypertension in Children: A Systematic Review and Meta-analysis. JAMA Pediatr. 2019: 1-10.

[12] Catherine Saez. Two-thirds of People in low \& middle-income countries with hypertension don't get treatment. Cardiovascular Diseases. [Internet]. 2019 [cited 2019 July 19] Available from: https://healthpolicy-watch.news/two-thirds-of-people-in-low-middleincome-countries-with-hypertension-dont-get-treatment/

[13] Kraudel Ryan. High Blood Pressureis a Global Health Tragedy. [Internet]. 2019 [cited 2020 March 9] Available from: https://valencell.com/blog/2019/09/high-blood-pressure-is-a-globalhealth-tragedy/. 
[14] Abegunde DO, Mathers CD, Adam T, Ortegon M, Strong K. The burden and costs of chronic diseases in low-income and middle-income countries. Lancet. 2007; 370(9603): 1929-38.

[15] Redfern A, Peters SA, Luo R, Cheng Y, Li C, Wang J, et al. Sex differences in the awareness, treatment, and control of hypertension in China: a systematic review with meta-analyses. Hypertension Research. 2019; 42: 273-283.

[16] Heart Disease and Stroke Statistics-2019 Update [Internet].2020 Heart [cited 2020 Mar 9]; Available from: https://professional.heart.org/professional/ScienceNews/UCM_50338 3 Heart-Disease-and-Stroke-Statistics---2019-Update.jsp

[17] Banegas JR, Conde TG. Epidemiología de La hipertensión arterial. Hipertensión y Riesgo Vascular. 2018; 34: 2-4. Spanish.

[18] Egan BM, Zhao Y, Axon RN, Brzezinski WA, Ferdinand KC. Uncontrolled and apparent treatment resistant hypertension in the United States, 1988 to 2008. Circulation. 2011; 124(9): 1046-1058.

[19] Petersen J, Malyutina S, Ryabikov A, Konstsevaya A, Kudryavtsey AV, Eggen AE, et al. Uncontrolled and apparent treatment resistant hypertension: a cross-sectional study of Russian and Norwegian 40 69 -year-olds. BMC Cardiovasc Disord. 2020; 20(1): 135.

[20] Firmo JOA, Peixoto SV, Loyola Filho AI, Souza-Júnior PRB, Andrade FB, Lima-Costa MF, et al. Comportamentos em saúde e o controle da hipertensão arterial: resultados do ELSI-BRASIL. Cad. Saúde Pública. 2019; 35( 7 ): e00091018. Portuguese.

[21] Tailakh A, Evangelista LS, Mentes JC, Pike NA, Phillips LR, Morisky DE. Prevalência, conscientização e controle da hipertensão nos países árabes: uma revisão sistemática. Nurs Health Sci. 2014; 16 (1): 126130. Portuguese.

[22] Gupta R, Gupta VP, Prakash H, Agrawal A, Sharma KK, Deedwania PC. Tendências de 25 anos na prevalência, conscientização, tratamento e controle da hipertensão em uma população urbana indiana: relógio cardíaco de Jaipur. IHJ. 2017; 70 (6): 802-7. Portuguese.

[23] Joffres M, Falaschetti E, Gillespie C, Robitaille C, Loustalot F, Poulter $\mathrm{N}$, et al. Prevalência de hipertensão, consciência, tratamento e controle em pesquisas nacionais da Inglaterra, EUA e Canadá, e correlação com acidente vascular cerebral e mortalidade por doenças cardíacas isquêmicas: um estudo transversal. BMJ Open. 2013; 3 (8): e003423. Portuguese.

[24] Van Rossum CT, van de Mheen H, Witteman JC, Hofman A, Mackenbach JP, Grobbee DE. Prevalência, tratamento e controle da hipertensão por fatores sociodemográficos em idosos holandeses. Hipertensos. 2000; 35 (3): 814-21. Portuguese.

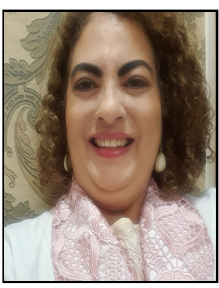

E.E.S Cestário: $\mathrm{PhD}$ in Health Sciences by State Medical School of São José do Rio Preto (FAMERP), São Paulo, Brail. Bachelor's at Medicina from State Medical School of São José do Rio Preto (FAMERP-1991). Lato sensu postgraduate in pharmacology from Don Bosco University. Specialist in Cardiology by the Brazilian Society of Cardiology. Specialist in Echocardiography and Ergometry. Title of Specialist in Intensive Therapy by the Brazilian Association of Intensive Medicine.

She is currently Professor of Medicine at the University Center of Votuporanga (UNIFEV). Assistant physician at the hypertension outpatient clinic at FAMERP. Member of the Artery Society; member of the American Society for Parenteral \& Enteral Nutrition and member of the American Society of Echocardiography. Doctor of the Santa Casa de Misericórdia and the Casa de Saúde- Hospital Unimed de Votuporanga. Principal Researcher at Cardiologic Clinic in Votuporanga. 